\title{
Spatial modelling of Lutzomyia (Nyssomyia) whitmani s.l. (Antunes \& Coutinho, 1939) (Diptera: Psychodidae: Phlebotominae) habitat suitability in the state of Mato Grosso, Brazil
}

\author{
Peter Zeilhofer/ ${ }^{+}$, Olga Patrícia Kummer, Emerson Soares dos Santos, Ana Lúcia Maria Ribeiro', \\ Nanci Akemi Missawa ${ }^{2}$ \\ Departamento de Geografia ${ }^{1}$ Faculdade de Ciências Médicas, Universidade Federal do Mato Grosso, Av. Haiti 193, 8060-618 Cuiabá, \\ MT, Brasil ${ }^{2}$ Secretaria Estadual de Saúde do Mato Grosso, Cuiabá, MT, Brasil
}

Lutzomyia (Nyssomyia) whitmani s.l. is the main vector of cutaneous leishmaniasis in state of Mato Grosso, but little is known about environmental determinants of its spatial distribution on a regional scale. Entomologic surveys of this sand fly species, conducted between 1996 and 2001 in 41 state municipalities, were used to investigate the relationships between environmental factors and the presence of the species, and to develop a spatial model of habitat suitability. The relationship between averaged CDC light trap indexes and 15 environmental and socio-economic factors were tested by logistic regression (LR) analysis. Spatial layers of deforestation tax and the Brazilian index of gross net production (IGNP) were identified as significant explanatory variables for vector presence in the LR model, and these were then overlaid with habitat maps. The highest habitat suitability in 2001 was obtained for the heavily deforested areas in the Central-North, South, East, and Southwest of Mato Grosso, particularly in municipalities with lower IGNP values.

Key words: Lutzomyia whitmani - phlebotomine - spatial modelling - Mato Grosso

In the state of Mato Grosso in the Central-Western region of Brazil, American cutaneous leishmaniasis disease (ACL) has been consistently reported since the year 2000 in more than $90 \%$ of the municipalities. In 2005, the disease was reported throughout the state, with most cases identified in the Central-Northern portion of Mato Grosso, a region of intensive agricultural activity (Sinop: 239 cases; Sorriso: 150 cases), as well as in Northwestern districts, where deforestation has intensified recently (Colniza: 148 cases; Juina 140 cases). According to Andrade et al. (2005), the Leishmania braziliensis group is the predominant complex causing human ACL infection. Less than $10 \%$ of cases are related to the Leishmania mexicana complex.

Lutzomyia (Nyssomyia) whitmani s.l. (Antunes \& Coutinho 1939) is considered the most important vector for the transmission of ACL in Mato Grosso (Costa et al. 2007, Ribeiro et al. 2007), but two other species are also important vectors for ACL in the state: Lutzomyia flaviscutellata (Mangabeira 1942a) and Lutzomyia migonei (França 1920), reported respectively in 37\% and 12\% of 41 sampled municipalities (Ribeiro et al. 2007). Originally associated with forested ecosystems (Lainson \& Shaw 1987), L. whitmani s.l. has developed anthropophilic habits and occurs under three different epidemiological profiles: sylvatic, sylvatic-modified and periurban

+ Corresponding author: pitalike@terra.com.br

Received 10 April 2008

Accepted 13 October 2008
(Basano \& Camargo 2004). However, little systematic work on the ecology and spatio-temporal distribution of L. whitmani s.l. is available for central Brazil.

In Mato Grosso, L. whitmani s.l. is ubiquitous and occurs in forests and woodlands of all biomes (Rain forest, Cerrado and Pantanal), as well as in anthropized and urbanized environments (Young \& Duncan 1994, Oliveira et al. 2006, Souza et al. 2004). During an 18-month survey in the municipality of Várzea Grande, Mato Grosso, Missawa and Dias (2007) did not find significant relationships between vector density and environmental factors such as temperature, humidity or rainfall. In Northern Mato Grosso, Azevedo et al. (2002) reported high densities of L. whitmani s.l. in an area with a stronger degradation of vegetation cover. The domiciliation of L. whitmani s.l. in rural settlements of the Brazilian government's agrarian reform program was reported in the municipalities of Chapada dos Guimarães and Nova Ubiratã by Rodrigues et al. (2003), suggesting that precarious socioeconomic conditions favour the presence of L. whitmani s.l. Recently, captures conducted in 2007 diagnosed L. whitmani s.l. in the urban areas of Cuiabá and Várzea Grande as well (ALM Ribeiro unpublished observations). In other Brazilian regions, it has been suggested that the structural characteristics of houses may influence the presence of $L$. whitmani s.l. (Falqueto 1995, Campbell et al. 2000). Furthermore, the recent review by Costa et al. (2007) of the geographic distribution of ACL vectors in Brazil provided limited information on L. whitmani s.l. presence in Mato Grosso. The vector was reported for only four municipalities. Other surveys of phlebotomine fauna including L. whitmani s.l. were spatially restricted to selected municipalities (Azevedo et al. 2002, Ribeiro et al. 2002, Costa et al. 2003, Rodrigues 
et al. 2003). Later, Ribeiro et al. (2007) noted the presence of L. whitmani s.l. in 33 of 41 sampled municipalities of the state of Mato Grosso.

To overcome the constraint of limited resources available for vector monitoring, habitat suitability can be spatially analyzed by risk factor analysis (Ready et al. 1998). Remote Sensing and Geographical Information Systems (GIS) for spatial data processing, techniques such as Ecological Niche Analysis (Stockwell \& Peterson 2002, Peterson \& Shaw 2003), Genetic Algorithm Rule-Set Prediction (GARP) (Nieto et al. 2006) or Logistic Regression (LR) (Gebre-Michael et al. 2004, Sattler et al. 2005) can provide a perspective on the geographic distributions of species. Spatial predictions about L. whitmani s.l. habitats in South America are extremely rare. Petersen and Shaw (2003) presented a super-regional study on Lutzomyia habitats in Southern Brazil and adjacent regions, including Central-Western Brazil, Paraguay and Argentina. At this scale, the authors identified geoecological factors such as elevation, annual precipitation and mean temperature to have predictive value for Lutzomyia habitat mapping.

However, because L. whitmani s.l. was found to be highly anthropophilic in the Amazon (Campbell-Lendrum et al. 1999) and Cerrado savannahs (Rodrigues et al. 2003), the vector densities are believed to be linked to socio-economic and housing conditions (Falqueto 1995, Campbell-Lendrum et al. 2000, Rodrigues et al. 2003). For this reason, in the present study have evaluated the influence of socio-economic as well as other environmental determinants on the spatial distribution of $L$. whitmani s.l. and to examine how the selected variables can explain the heterogeneity of the habitat characteristics. The results were then used to develop a spatial model of the habitat suitability for the period of conducted field surveys.

\section{MATERIALS AND METHODS}

Entomologic survey - L. whitmani s.l. data were obtained from entomological surveys of phlebotomine species, conducted between 1996-2001 by the Entomologic Laboratory of the National Foundation of Public Health and the Mato Grosso State Department of Public Health. Captures with CDC light traps were carried out in 41 of the 139 municipal districts of the state of Mato Grosso (Fig. 1).

Sampled districts are well stratified according to the environmental characteristics of the entire state: $35 \%$ of the sampled districts are located in the Amazon rainforest biome, which covers $48 \%$ of the state. Fifty five percent are in the Cerrado region, which covers $47 \%$ of the state, and $10 \%$ are in the Pantanal floodplain, which covers $5 \%$ of the state.

In each of the 172 campaigns, between 9-15 CDC traps were proportionally distributed in intra (indoor), peri (pigsty and chicken houses) and forest border ecotopes. The traps were installed at dusk for a period of $12 \mathrm{~h}$.

Collected specimens were stored in $70 \%$ alcohol, cleared, and species were identified according to Young and Duncan (1994). For each trap, the trap index (TI) (number of individuals per trap per night) for $L$. whit-
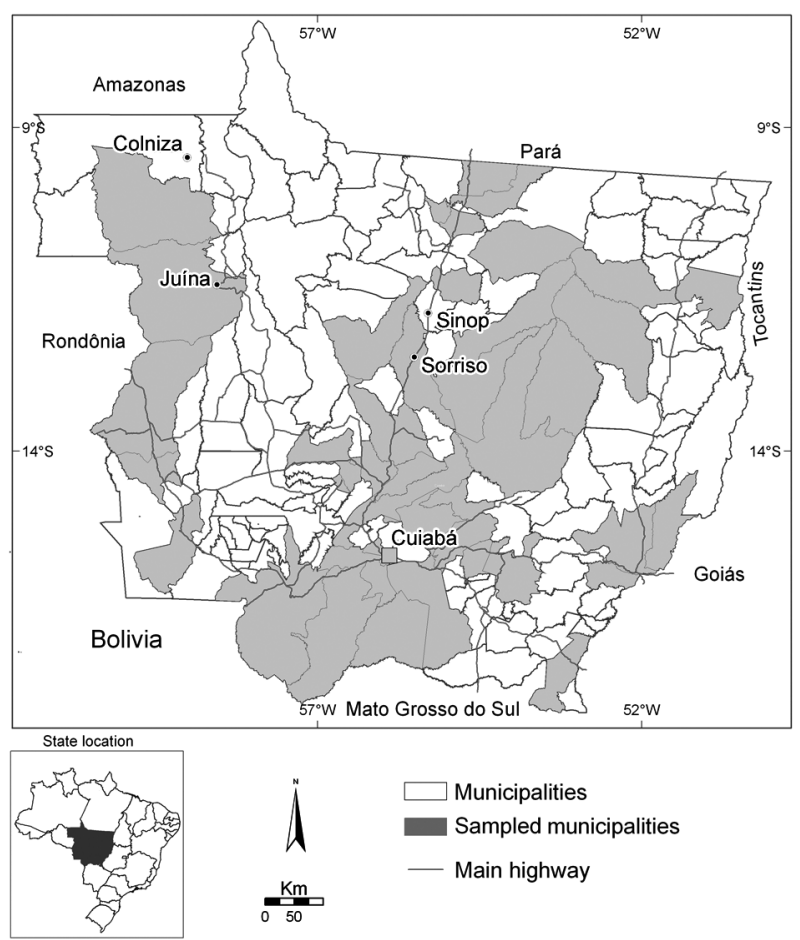

Fig. 1: state of Mato Grosso with sampled municipalities. The four labelled municipalities reported more than 140 American cutaneous leishmaniasis cases in 2005.

mani s.l. was calculated. TI values were then averaged for each municipality. If more than one campaign was conducted per municipality, the TIs of the campaigns were averaged. Field work was undertaken throughout a 6 -year period, with samplings occurring in different seasons (Table I). Since mean TI values from the sampling campaigns had a non-Gaussian distribution if grouped according to season and year of campaign, non-parametric Kruskal-Wallis analysis was conducted to test if averages from the municipalities could be joined for spatial model building.

Spatial data processing - GIS analysis, including the geo-referencing of data layers, image classification, Digital Elevation Model (DEM) processing and overlay procedures was conducted with the ArcGIS 9.1 software (ESRI, Redlands). A total of 15 spatial datasets were developed to test their predictive value for habitat suitability mapping of L. whitmani s.l. (Table II). All layers were geo-referenced to the polyconic projection (Datum SAD69) of the 1:1,000,000 Brazilian cartographic base, available digitally from the IBGE (http://www.ibge.gov. br). All attributes were spatially aggregated to the borders of state municipalities.

Vegetation cover, land use and deforestation had already been found to affect vector distribution and the epidemiological profile of ACL (WHO 1990, Rangel 1995, Campbell-Lendrum et al. 2001). Therefore, a four-class layer of vegetation/land use cover (forest, cerrado savannah, agriculture and water) was elaborated by a supervised Maximum Likelihood classification of the Normalized Difference Vegetation Index (NDVI) 
TABLE I

Summary of the entomologic survey conducted in 41 municipalities in Mato Grosso between 1996-2001

\begin{tabular}{|c|c|c|c|c|}
\hline Municipality & $\begin{array}{c}\text { Campaigns } \\
\mathrm{n}\end{array}$ & $\begin{array}{c}\text { Sites } \\
\mathrm{n}\end{array}$ & $\operatorname{Month}(\mathrm{s}) /$ Year(s) ${ }^{a}$ & $\begin{array}{c}\text { Average trap index of } \\
\text { Lutzomyia (Nyssomyia) } \\
\text { whitmani s.l. }\end{array}$ \\
\hline Alto Araguaia & 2 & 2 & $05 / 1998$ & 0.3 \\
\hline Araguaiana & 5 & 5 & $06 / 2000$ & 0.1 \\
\hline Arenápolis & 2 & 2 & $05 / 1997$ & 1.6 \\
\hline Aripuanã & 3 & 3 & $02 / 1998(2 x), 04 / 1998$ & 0.0 \\
\hline Barão de Melgaço & 12 & 11 & $07 / 1996(2 x), 01 / 2000(10 x)$ & 0.1 \\
\hline Barra do Garças & 8 & 7 & $05 / 2000(5 x), 11 / 2001(3 x)$ & 7.0 \\
\hline Cáceres & 2 & 2 & $05 / 1999$ & 5.4 \\
\hline Campinápolis & 11 & 11 & $05 / 1999$ & 0.0 \\
\hline Campo Verde & 1 & 1 & $09 / 2001$ & 0.8 \\
\hline Chapada dos Guimarães & 2 & 2 & 07/1996, 04/1998 & 8.9 \\
\hline Cláudia & 1 & 1 & $04 / 1997$ & 20.0 \\
\hline Comodoro & 2 & 2 & $12 / 1999$ & 0.0 \\
\hline Diamantino & 2 & 2 & $03 / 2001$ & 0.7 \\
\hline Dom Aquino & 3 & 3 & 07/1998 (2x), 09/2001 & 2.0 \\
\hline Feliz Natal & 8 & 8 & $08 / 2001$ & 0.3 \\
\hline Gaúcha do Norte & 2 & 2 & $12 / 1999$ & 0.0 \\
\hline Guarantã do Norte & 3 & 3 & $07 / 2001$ & 0.2 \\
\hline Juína & 1 & 1 & 09/1996 & 0.1 \\
\hline Marcelândia & 3 & 3 & $08 / 2001$ & 0.1 \\
\hline Matupá & 6 & 5 & 05/1996 (2x), 11/2001 (4x) & 0.2 \\
\hline Nobres & 2 & 2 & $11 / 2000,01 / 2001$ & 1.9 \\
\hline Nortelândia & 3 & 3 & 02/1997, 05/1997, 06/1997 & 1.8 \\
\hline Nossa Sra do Livramento & 7 & 7 & 05/1996, 07/2001 (6x) & 2.6 \\
\hline Nova Lacerda & 1 & 1 & $12 / 1999$ & 0.0 \\
\hline Nova Brasilândia & 4 & 4 & 07/1996, 09/1996, 07/2000, 09/2001 & 5.9 \\
\hline Nova Guarita & 2 & 2 & $08 / 1999$ & 7.5 \\
\hline Nova Mutum & 2 & 2 & $10 / 1999$ & 0.0 \\
\hline Nova Ubiratã & 5 & 5 & $12 / 2001$ & 0.0 \\
\hline Paranatinga & 3 & 3 & 11/1997, 12/2001 (2x) & 5.5 \\
\hline Poconé & 10 & 10 & $08 / 1999(4 x), 11 / 2000(6 x)$ & 11.2 \\
\hline Pontal do Araguaia & 3 & 3 & $06 / 2000$ & 0.2 \\
\hline Pontes e Lacerda & 1 & 1 & $06 / 1999$ & 0.7 \\
\hline Poxoréo & 7 & 7 & $08-10 / 1998(3 x), 12 / 2000(4 x)$ & 12.8 \\
\hline Querência & 2 & 2 & $06 / 2001$ & 0.0 \\
\hline Rosário Oeste & 2 & 1 & $--/ 2000,--/ 2001$ & 17.2 \\
\hline São Félix do Araguaia & 2 & 1 & $12 / 1999,06 / 2001$ & 0.0 \\
\hline Santo Antônio do Leverger & 3 & 3 & $07 / 1996$ & 0.6 \\
\hline Sorriso & 6 & 6 & $12 / 1998(5 x), 05 / 2000$ & 3.2 \\
\hline Tapurah & 1 & 1 & $10 / 1999$ & 0.0 \\
\hline Terra Nova do Norte & 1 & 1 & $08 / 1999$ & 1.8 \\
\hline Várzea Grande & 26 & 24 & $\begin{array}{l}07 / 1998(2 x), 05 / 1999(2 x), 08 / 2000(9 x), \\
09 / 2000(9 x), 10 / 2000(2 x), 12 / 2000(3 x)\end{array}$ & 0.2 \\
\hline
\end{tabular}

$a$ : number of campaigns in parenthesis when there were more than one campaign in such a month/year.

of the Moderate Resolution Imaging Spectroradiometer, MODIS remote sensing system. The product used (MOD13Q1 - V4) has a spatial resolution of $250 \mathrm{~m}$ and is composed of multi-temporal images from a 16-day period from mid-March 2001, to avoid cloud contamination (Huete et al. 2002). The original NDVI, widely known as an indicator of green vegetation density, was further tested for its predictive power (Cardenas et al. 2006).

The state of Mato Grosso includes three of Brazil's main biomes: Cerrado (savannah), Amazon (evergreen and transitional forests) and the Pantanal (tropical floodplain formations). The percentage of each biome inside the municipalities was extracted from a thematic map of administrative boundaries of Mato Grosso, as obtained digitally from IBGE (2000).

Macroclimate zoning and its topography-based modifications define Lutzomyia habitat characteristics such as temperature and precipitation (Peterson \& Shaw 2003). The altitude dependence of the phlebotomine fauna has also been reported (Ferreira et al. 2001, 
TABLE II

Explanatory data sets tested in the Logistic Regression models for habitat suitability mapping of Lutzomyia (Nyssomyia) whitmani s.l. All data sets are spatially aggregated to municipalities

\begin{tabular}{|c|c|c|c|}
\hline Data set & Description & Origin & Data scale \\
\hline Land & Land cover & MODIS imagery classification from $05 / 03 / 2001$ & 4 classes \\
\hline $\operatorname{Defo}^{a}$ & Area deforested during & $\mathrm{SEMA}^{b}$ deforestation survey of visual & \\
\hline NDVI & $\begin{array}{l}\text { entomologic campaign(s) } \\
\text { Normalized difference vegetation index }\end{array}$ & $\begin{array}{l}\text { Landsat ETM imagery interpretation } \\
\text { MODIS } 16 \text { day composite (www.modis.umiacs.umd.edu) } \\
\text { from mid-March } 2001\end{array}$ & real \\
\hline Biom & Percentage of main biomes & IBGE $(2000)$ & real \\
\hline Elev & Mean elevation & SRTM Digital elevation model (www.usgs.gov) & real \\
\hline Prec & Mean annual precipitation & $\begin{array}{l}\text { Interpolated from isohyets of socio-economic } \\
\text {-ecological zoning of Mato Grosso (SEPLAN 2005) }\end{array}$ & real \\
\hline Temp & Mean annual temperature & $\begin{array}{l}\text { Interpolated from isohyets of socio-economic } \\
\text {-ecological zoning of Mato Grosso (SEPLAN 2005) }\end{array}$ & real \\
\hline $\mathrm{Alph}^{a}$ & Alphabetization tax of adults & PNUD (2003) & real \\
\hline $\mathrm{INCO}^{a}$ & Income & PNUD (2003) & real \\
\hline $\mathrm{LIFE}^{a}$ & Life expectancy at birth & PNUD (2003) & real \\
\hline $\mathrm{NPSE}^{a}$ & Net primary school enrollment rate of adults & PNUD (2003) & real \\
\hline IALP $^{a}$ & Index of alphabetization & PNUD (2003) & real \\
\hline IEDU $^{a}$ & Index of education & PNUD (2003) & real \\
\hline $\operatorname{IHDE}^{a}$ & Human development index & PNUD (2003) & real \\
\hline $\mathrm{IGNP}^{a}$ & Index of gross national product & PNUD (2003) & real \\
\hline
\end{tabular}

$a$ : datasets aggregated per municipality according to entomologic sampling period; $b$ : State Environmental Agency of Mato Grosso.

Margonari et al. 2006). A DEM from the Shuttle Radar Topography Mission with a 90-m spatial resolution was obtained from the United States Geological Survey in order to parameterize average elevations of municipalities. The average annual precipitation (1983-2004) and average annual temperatures were interpolated with a spline-in-tension algorithm (Smith \& Wessel 1990) from isohyets on a 1:1,500,000 scale, available from the socioeconomic and ecological zoning of state of Mato Grosso (SEPLAN 2005).

Eight socio-economic data sets, aggregated for each municipality, were determined for the year or averaged for the years of entomologic sampling in the respective municipality. The datasets included the alphabetization tax of adults, income, life expectancy at birth, net primary school enrolment rate of adults and derived indices such as the index of alphabetization, index of education, index of human development and index of gross national product (IGNP). All of these are available from IBGE on an annual basis.

Models for habitat suitability mapping of L. whitmani s.l. were developed by multiple LR analysis, using the "backward conditional" procedure (Hosmer \& Lemeshow 1989). To reduce the number of explanatory data sets for spatial model building, a two-step procedure was adopted. First, correlation and regression analyses were applied to assess co-linearity among exploratory variables (Elmstahl \& Gullberg 1997). Then, each variable was submitted to a univariate LR analysis. Only if its significance level (p) was found to be lower than 0.10 , was a variable considered for further analysis. If co-linearity was observed between two variables (Spearmen Rank correlation higher than 0.8 ), only the variable with the higher significance level was considered in the multivariate LR analysis. Model fitting was repeated for cut-off values of average TIs of 0.5 , $1,2,3,5$ and 10 to evaluate the sensitivity and specificity of the model. Validation of regression models was conducted using standard LR outputs from SPSS, 10.0 (SPSS Inc), evaluating significance levels of the regression coefficients and contingency table with commission, omission and overall errors.

\section{RESULTS}

L. whitmani s.l. is common throughout the state of Mato Grosso. Specimens were captured in 33 of 41 sampled municipalities, with a maximum average TI of 20.0 for the municipality of Cláudia, located in the CentralNorthern of Mato Grosso, followed by Rosário Oeste (17.2) in the Central-Southern (Fig. 2).

If the TIs of the 172 sampling campaigns are grouped according to seasonal period of capture, i.e., dry season (May-October) and rainy season (November-April), a Kruskal-Wallis test strongly rejects the null hypothesis that there are significant differences between TIs $(p=0.79)$ from the dry and the rainy seasons (Fig. 3A).

Samplings from 1996 and 1997 appeared have higher medians of TI values, particularly compared with samplings from 1999, but differences were not found to be significant $(\mathrm{p}=0.07)$ (Fig. 3B). Therefore, TI averages from all sampling campaigns were considered available for spatial model building.

Two explanatory datasets were found to have highly a significant relationship with binarized L. whitmani s.l. TIs aggregated to the 41 municipalities (Table III). These datasets are the deforestation taxes, which were derived from the supervised land cover classification of multispectral MODIS imagery and the IGNP (Figs 4, 5). 
Deforested areas were identified by the maximum likelihood classifier with accuracies of $95.7 \%$ (producers' accuracy) and $96.7 \%$ (users' accuracy), respectively. Inside the Pantanal floodplain, in the Southwestern municipalities, classification results were corrected by visual imagery interpretation, as natural dry grassland

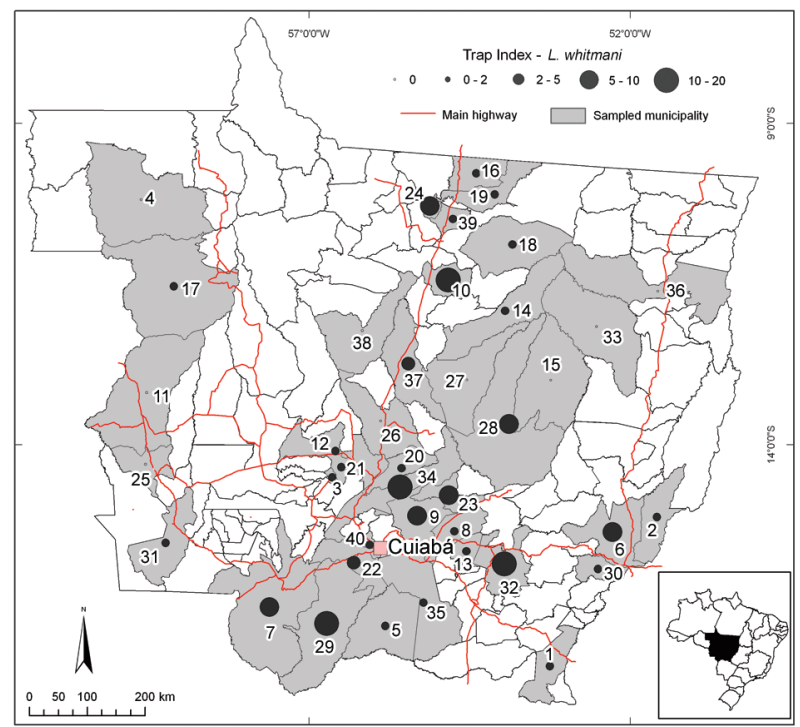

Sampled municipality

1 - Alto Araguaia

15 - Gaúcha do Norte

29 - Poconé

2 - Araguaiana

16 - Guarantă do Norte

30 - Pontal do Araguaia

3 - Arenápolis

4 - Aripuanã

5 - Barão de Melgaço

6 - Barra do Garças

7 - Cáceres

8 - Campo Verde

9 - Chapada dos Guimarãe

10 - Cláudia

11 - Comodoro

12 - Diamantino

13 - Dom Aquino

14 - Feliz Natal

17 - Juína

18 - Marcelândia

19 - Matupá

20 - Nobres

21 - Nortelândia

22 - N. Sra do Livramento

23 - Nova Brasilândia

24 - Nova Guarita

25 - Nova Lacerda

26 - Nova Mutum

27 - Nova Ubiratã

28 - Paranatinga

Fig. 2: averaged CDC light trap indexes of Lutzomyia (Nyssomyia) whitmani s.l. in sampled municipalities in the state of Mato Grosso. is easily confused with deforestation. The probability of vector presence increased in municipalities with higher deforestation taxes and lower IGNP. The best modelling performance was obtained for a cut-off value of one, resulting in an overall accuracy of $77.5 \%$.

Municipalities with the highest habitat suitability
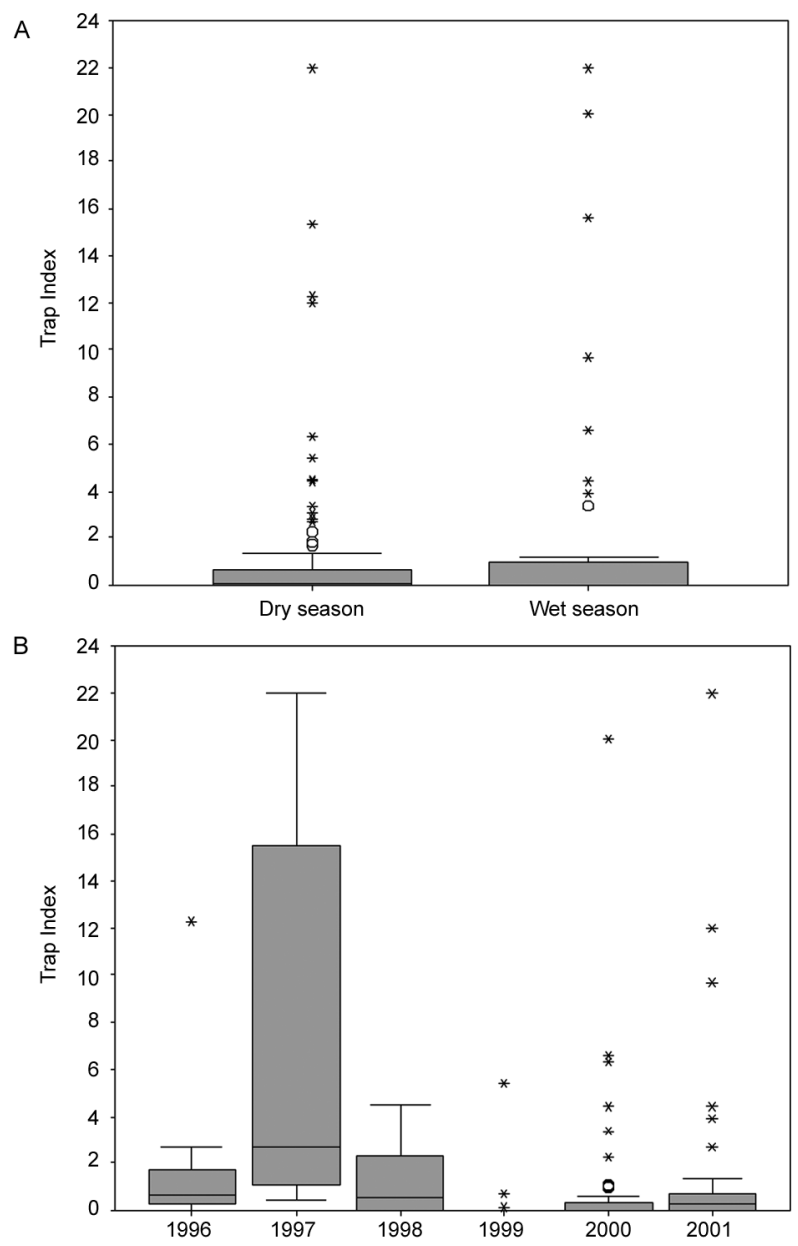

Fig. 3: trap indexes values of sampling campaigns $n=172$ grouped according to sampling period (A) and year of survey (B).

TABLE III

Coefficients (B) of multiple logistic regression (backward conditional) used for spatial modeling probability (logit) of a trap index above one and cross validation

\begin{tabular}{lcccccc}
\hline & $\mathrm{B}$ & S.E. & Wald & $\mathrm{df}$ & Sig. & $\operatorname{Exp(B)}$ \\
\hline Deforestation rate & 0.041 & 0.021 & 3.761 & 1 & 0.0032 & 1.042 \\
Index of gross net production & -3.647 & 1.458 & 6.255 & 1 & 0.0012 & 0.026 \\
\hline
\end{tabular}

\begin{tabular}{lrrrr}
\hline & \multicolumn{3}{c}{ Predicted } & Percentage correct \\
\cline { 2 - 5 } Observed & 0 & 0 & 1 & \\
& 1 & 3 & 20 & 64.7 \\
Overall percentage & & & & 87.0 \\
\cline { 2 - 5 } & & & & 77.5
\end{tabular}

df: degrees of freedom; $\operatorname{Exp}(B)$ : eraised to the value of the regression coefficient B; SE: standard error; Sig: significance level; Wald: wald statistic. 


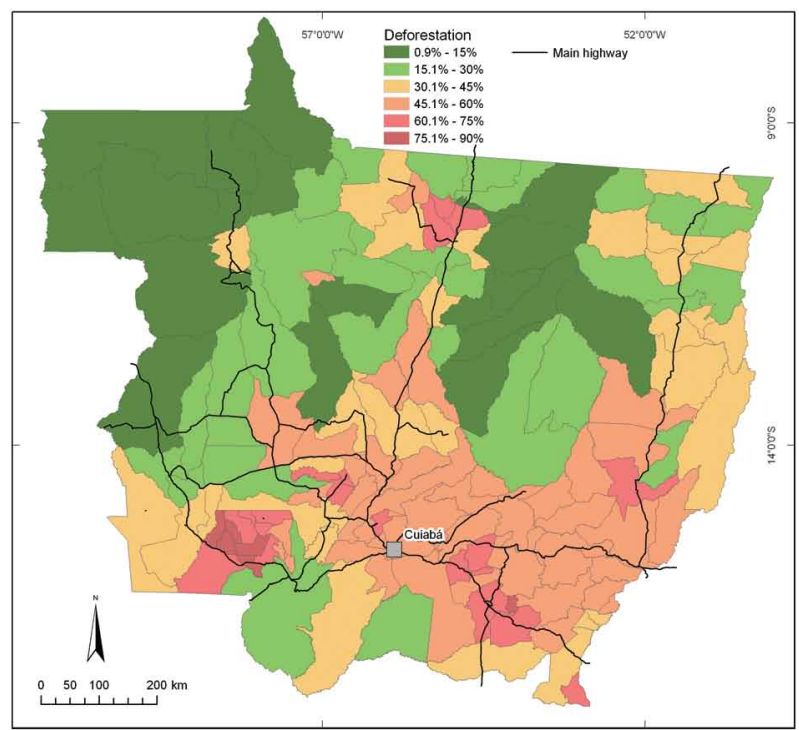

Fig. 4: spatial patterns of deforestation tax in Mato Grosso in 2001.

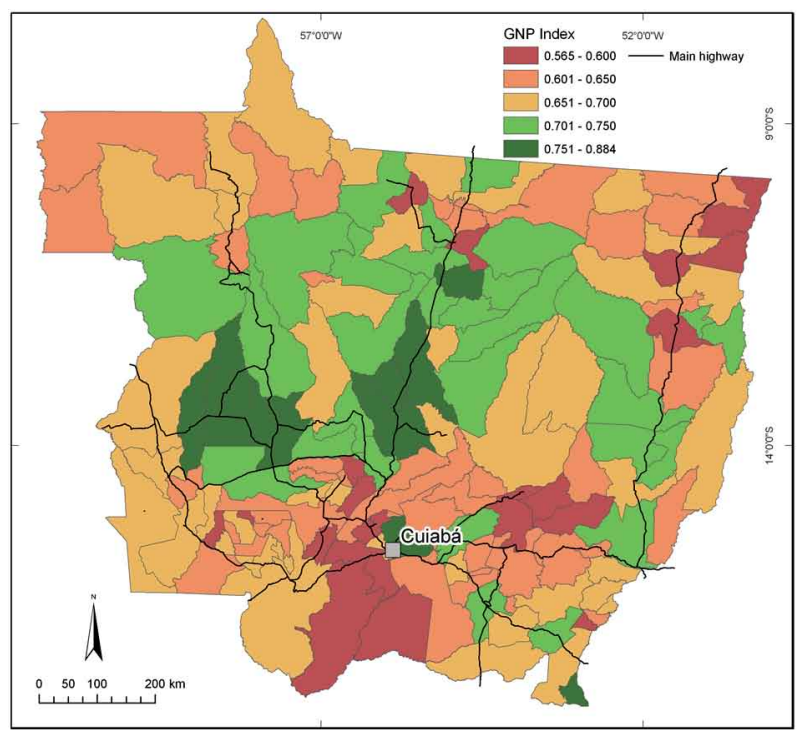

Fig. 5: spatial patterns of the gross national product index (IGNP) in Mato Grosso in 2001.

of L. whitmani s.l. are in the Southern of Mato Grosso, including two of the most densely populated municipalities: Poconé and Cáceres, in the Pantanal floodplain. High habitat suitability is also found in the Northern direction, following the BR-163 highway, which is the main axis of agricultural expansion in the savannah and Amazon biomes of the Central-Northern and Southeastern of Mato Grosso (Rosário Oeste, Cláudia, Chapada dos Guimarães, Poxoréu). The municipalities in Northern Mato Grosso with high habitat suitability present low IGNPs and deforestation taxes above $60 \%$.

\section{DISCUSSION}

L. whitmani s.l. is common throughout the state of Mato Grosso. Specimens were captured in 33 of 41 sampled municipalities, confirming its tolerance of dif- ferent vegetation types and climatic conditions (Costa et al. 2007). The spatio-temporal aggregation procedure for spatial habitat simulation, i.e., comparison of results from a 6-year entomological survey was based on the findings that there are no significant seasonal or inter-annual differences in the values of the TIs, which are highly variable according to the municipalities. A similar finding was reported by Missawa and Dias (2007) for the Várzea Grande municipality, where no significant correlation between climatic variables (temperature, humidity and rainfall) and phlebotomine density was observed. While no long-term entomological studies of $L$. whitmani s.l. in Mato Grosso are available to compare inter-annual variability of vector presence, the reports of ACL cases in more than $90 \%$ of the municipalities since 2000 indicate, that the principal vector is permanently present in the entire state, at least throughout the last decade.

Spatial distribution of $L$. whitmani s.l. in Mato Grosso is positively correlated with deforestation rates and negatively correlated with the IGNP, a primary indicator of socio-economic development. These findings reinforce statements that $L$. whitmani s.l. is highly anthrophilic in the Brazilian rain forest, transitional forest and Cerrado savannahs (Campbell-Lendrum et al. 1999, Rodrigues et al. 2003) and that deforestation does not result in a general loss of L. whitmani s.l. habitats. The finding that favourable habitats occur in municipalities with weaker economic development confirms that vector occurrence is linked to precarious living conditions, found either in rural settlements of the Brazilian government's agrarian reform program (Rodrigues et al. 2003), or in municipalities with intense migratory flows of people from lower social levels.

There is known scale dependence in the mapping of specimen occurrence through spatial predictors (Chust et al. 2004, Hill \& Hamer 2004, Lira-Noriega et al. 2007). The comparison of our findings with the superregional spatial simulations presented in the comprehensive work of Petersen and Shaw (2003) shows the strong scale dependence of L. whitmani s.l. habitat models and the importance of forthcoming vector monitoring to consolidate modelling efforts with higher spatial resolutions. Our findings did not show a significant influence of elevation or average annual temperature on habitat suitability, as described by Petersen and Shaw (2003). We suggest that this may be due to the scale of our modelling approach: elevation differences in the Mato Grosso territory are about $700 \mathrm{~m}$ and their resulting orographic effects on temperatures are much lower than in a super-regional approach that would include coastal regions and the Andes mountain ranges (Petersen \& Shaw 2003). Secondly, both the thematic map of recorded L. whitmani s.l. presence exposed by Costa et al. (2007) and the spatial prediction in the model of Petersen and Shaw (2003) indicate a zone of reduced habitat suitability for the central parts of state of Mato Grosso, which is contrary to our findings. This difference may result from the absence of entomological data in the previous studies. These comparisons emphasize the importance of regional models for an accurate prediction of vector habitat suitability and continuing work on entomologic surveys in the state of Mato Grosso. 


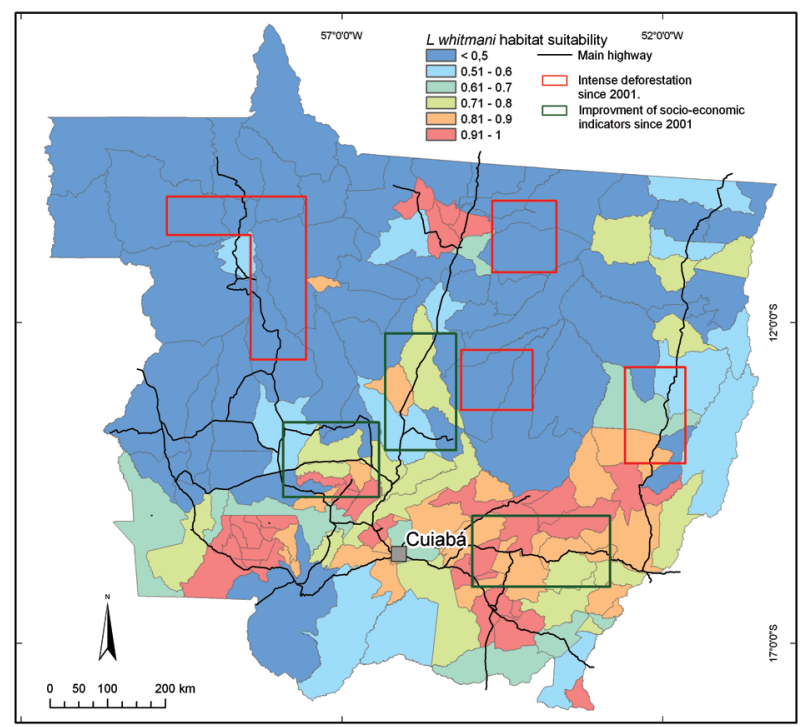

Fig. 6: habitat suitability of Lutzomyia (Nyssomyia) whitmani s.l., simulated for 2001, overlaid with zones of intense deforestation activities (red rectangles) and improvement of gross national product index (green rectangles) after 2001.

Another important point to mention is that the above discussion of L. whitmani s.l. habitat suitability (Fig. 6) refers to a simulation of the situation around the year 2000. The rapid socio-environmental transformations in Mato Grosso since 2000-2001 have likely changed habitat suitability of $L$. whitmani s.l. in the state, shifting the habitats Northward into the regions of recent deforestation (red rectangles in Fig. 6). On the other hand, habitat suitability has probably decreased in municipalities with consolidated agro-industrial production systems, presenting substantial growth in the IGNP during the last five years (green rectangles). Therefore, the applied LR analysis should be seen not only as a spatial prediction at a particular moment, but more generally as a procedure to improve knowledge about the causal relationships between vector presence and socio-environmental factors.

The present study on the habitat modelling of L. whitmani s.l. in Mato Grosso is based on a comprehensive survey of sand flies in the state (Ribeiro et al. 2007), showing a vector presence much more widely distributed than previously reported. Thus, the highest TIs in urbanized areas and regions of intense agricultural expansion demonstrate the ongoing domiciliation of the vector. Geographical distribution patterns are linked to deforestation rates and the IGNP. Comparisons with previous modelling efforts show that there is high demand for further vector monitoring and development of spatially fine grained habitat mapping of $L$. whitmani $\mathrm{s} . l$. The relationship between vector presence and socioenvironmental factors can be explained through regression studies that then permit the elaboration of predictive maps. The analysis procedures should be repeated based on updated entomologic surveys and spatial data layers to represent actual habitat suitability.

\section{ACKNOWLEDGMENTS}

To the technicians of the Entomology Laboratory, who carried out extensive field and laboratory work essential for the development of this research, and the two anonymous reviewers whose comments were fundamental in improving the present paper.

\section{REFERENCES}

Andrade ASR, Fernandes O, Hueb M, Carvalho MLR, Fontes CJ, Melo MN 2005. The use of radionuclide DNA probe technology for epidemiological studies of tegumentary leishmaniasis in Mato Grosso State. Brazil Arch Biol Techn 48: 201-204.

Azevedo ACR, Souza NA, Meneses CRV, Costa WA, Lima JB, Rangel EF 2002. Ecology of sand flies (Diptera: Psychodidae: Phlebotominae) in the North of the state of Mato Grosso, Brazil. Mem Inst Oswaldo Cruz 97: 459-469.

Basano SA, Camargo LMA 2004. American cutaneous leishmaniasis: history, epidemiology and prospects for control. Rev Bras Epidemiol 7: 328-337.

Campbell-Lendrum DH, Brandão-Filho SP, Pinto MC, Vexenat A, Ready PD, Davies CR 2000. Domesticity of Lutzomyia whitmani (Diptera: Psychodidae) populations: field experiments indicate behavioural differences. Bull Entomol Res 90: 41-48.

Campbell-Lendrum DH, Dujardin JP, Martinez E, Feliciangeli MD, Perez JE, Silans LN, Desjeux P 2001. Domestic and peridomestic transmission of American cutaneous leishmaniasis: changing epidemiological patterns present new control opportunities. Mem Inst Oswaldo Cruz 96: 159-162.

Campbell-Lendrum DH, Pinto MC, Brandão-Filho SP, De Souza AA, Ready PD, Davies CR 1999. Experimental comparison of anthropophily between geographically dispersed populations of Lutzomyia whitmani (Diptera: Psychodidae). Med Vet Entomol 13: 299-309.

Cardenas R, Sandoval CM, Rodríguez-Morales AJ, Franco-Paredes C 2006. Impact of climate variability in the occurrence of leishmaniasis in Northeastern Colombia. Am J Trop Med Hyg 75: 273-277.

Chust G, Pretus JL, Ducrot D, Ventura D 2004. Scale dependency of insect assemblages in response to landscape pattern. Landscape Ecology 19: 41-57.

Costa LB, Bertúlio MA, Rodrigues H, Lima GBM, Ramos SR, Moraes Filho VC, Ribeiro ALM, Souza CO, Silva AM, Barros IM 2003. Ocorrência de flebotomíneos vetores da Leishmaniose Visceral nos municípios do Estado de Mato Grosso. Rev Abrasco 8: 639.

Costa SM, Cechinel M, Bandeira V, Zannuncio JC, Lainson R, Rangel EF 2007. Lutzomyia (Nyssomyia) whitmani s.l. (Antunes \& Coutinho, 1939) (Diptera: Psychodidae: Phlebotominae): geographical distribution and the epidemiology of American cutaneous leishmaniasis in Brazil. Mini-review. Mem Inst Oswaldo Cruz 102: 149-153.

Elmstahl S, Gullberg B 1997. Bias in diet assessment methods-consequences of collinearity and measurement errors on power and observed relative risks. Int J Epidemiol 26: 1071-1079.

Falqueto A 1995. Especificidade alimentar de flebotomíneos em duas áreas endêmicas de leishmaniose tegumentar no estado do Espirito Santo, PhD Thesis, Fundação Oswaldo Cruz, Rio de Janeiro, $84 \mathrm{pp}$.

Ferreira AL, Sessa PA, Varejão JBM, Falqueto A 2001. Distribution of sand flies (Diptera: Psychodidae) at different altitudes in an endemic region of American cutaneous leishmaniasis in the state of Espírito Santo, Brazil. Mem Inst Oswaldo Cruz 96: 1061-1067. 
Gebre-Michael T, Malone JB, Balkew M, Ali A, Berhe N, Hailu A, Herzi AA 2004. Mapping the potential distribution of Phlebotomus martini and P. orientalis (Diptera: Psychodidae), vectors of kala-azar in East Africa by use of geographic information systems. Acta Trop 90: 73-86.

Hill JK, Hamer KC 2004. Determining impacts of habitat modification on diversity of tropical forest fauna: the importance of spatial scale. $J$ Appl Ecol 41: 744-754.

Hosmer DW, Lemeshow S 1989. Applied logistic regression, Wiley Interscience, New York, $307 \mathrm{pp}$.

Huete A, Didan K, Miura T, Rodriguez EP, Gao X, Ferreira LG 2002. Overview of the radiometric and biophysical performance of the MODIS vegetation indices. Rem Sensing Environm 83: 195-213.

IBGE - Instituto Brasileiro de Geografia e Estatística 2000. Mapas dos Biomas Brasileiros. Available from geofpt.ibge.gov.br/mapas.

Lainson R, Shaw JJ 1987. Evolution, classification and geographic distribution. In $\mathrm{W}$ Peters, $\mathrm{R}$ Killick-Kendrick, The Leishmaniases in Biology and Medicine. Biology and Epidemiology, Vol 1. Academic Press Inc, London, p. 1-120.

Lira-Noriega A, Soberón J, Navarro-Sigüenza AG, Nakazawa Y, Townsend Peterson A 2007. Scale dependency of diversity components estimated from primary biodiversity data and distribution maps. Divers Distrib 13: 185-195.

Margonari C, Freitas CR, Ribeiro RC, Moura ACM, Timbó M, Gripp AH, Pessanha JE, Dias ES 2006. Epidemiology of visceral leishmaniasis through spatial analysis, in Belo Horizonte municipality, state of Minas Gerais, Brazil. Mem Inst Oswaldo Cruz 101: 31-38.

Missawa NA, Dias ES 2007. Phlebotomine sand flies (Diptera: Psychodidae) in the municipality of Várzea Grande: an area of transmission of visceral leishmaniasis in the state of Mato Grosso, Brazil. Mem Inst Oswaldo Cruz 102: 913-918.

Nieto P, Malone JB, Bavia ME 2006. Ecological niche modeling for visceral leishmaniasis in the state of Bahia, Brazil, using genetic algorithm for rule-set prediction and growing degree day-water budget analysis. Geospat Health 1: 115-126.

Oliveira ALL, Paniago AMM, Dorval MEC, Oshiro ET, Leal CR, Sanches M, Cunha RV, Bóia MN 2006. Foco emergente de leishmaniose visceral em Mato Grosso do Sul. Rev Soc Bras Med Trop 39: $446-450$

Peterson TA, Shaw J 2003. Lutzomyia vectors for cutaneous leishmaniasis in Southern Brazil: ecological niche models, predicted geographic distributions, and climate change effects. Int J Parasitol 33: 919-931.

PNUD - Programa das Nações Unidas para o Desenvolvimento 2003. Atlas do desenvolvimento. Available from: www.pnud. org.br/atlas.
Rangel EF 1995. Epidemiology of American cutaneous leishmaniasis in Brazil. In Tropical diseases, society and the environment. SAREC Documentation/TDR, Stockholm, p. 103-110.

Ready DP, Souza AA, Macario Rabelo JM, Day JC, Silveira FT, CampellLedrum D, Davies CR, Costa JML 1998. Phylogenetic species and domesticity of Lutzomyia whitmani at the south-east boundary of Amazonian, Brazil. Trans R Soc Trop Med Hyg 92: 159-160.

Ribeiro ALM, Missawa N, Zeilhofer P 2007. Distribution of phlebotomine sandflies (Diptera: Psychodidae) of medical importance in Mato Grosso state, Brazil. Rev Inst Med Trop Sao Paulo 49: $317-321$.

Ribeiro ALM, Oliveira RC, Miyazaki RD, Pignati WA 2002. Inventário dos vetores da Leishmaniose (Diptera: Psychodidae: Phlebotominae) em área de aproveitamento múltiplo de Manso, Chapada dos Guimarães, Nobres, Rosário Oeste e Nova Brasilândia/ Mato Grosso/Brasil. Rev Soc Bras Med Trop 35: 313.

Rodrigues H, Missawa NA, Costa LB, Lima GBM, Ramos SR, Moraes Filho VC, Souza CO, Ribeiro ALM, Silva AM, Barros IM 2003. A interferência humana como fator de agravamento ambiental e a domiciliação dos vetores da leishmaniose tegumentar americana no estado de Mato Grosso, no período de 2001 e 2002. Rev Abrasco 8: 414.

Sattler MA, Mtasiwa D, Kiama M, Premji Z, Tanner M, Killeen GF, Lengeler $\mathrm{CH} 2005$. Habitat characterization and spatial distribution of Anopheles spp. mosquito larvae in Dar es Salaam (Tanzania) during an extended dry period. Malar J 4: 4.

SEPLAN-MT-Secretaria de Estado de Planejamento e Coordenação Geral de Mato Grosso 2005. Zoneamento sócio-econômico ecológico. Relatório técnico consolidado de clima para o Estado de Mato Grosso, Vols. 1 e 2, Cuiabá, 83 pp.

Smith WHF, Wessel P 1990. Gridding with continous curvature splines in tension. Geophysics 55: 293-305.

Souza CM, Pessanha JE, Barata RA, Monteiro EM, Costa DC, Dias ES 2004. Study on phlebotomine sand fly (Diptera: Psychodidae) fauna in Belo Horizonte, state of Minas Gerais, Brazil. Mem Inst Oswaldo Cruz 99: 795-803.

Stockwell DRB, Peterson AT 2002. Effects of sample size on accuracy of species distribution models. Ecological Modelling 148: 1-13.

WHO - World Health Organization 1990. Control of leishmaniasis. Report of a WHO Expert Committee, Technical Report Series, WHO, Geneva, n 793, 158 pp.

Young DG, Duncan MA 1994. Guide to the identification and geographic distribution of Lutzomyia sand flies in Mexico, the West Indies, Central and South America (Diptera: Psychodidae). Associate Publishers American Entomological Institute, Florida, 888 pp. 